\title{
Hepatitis B Virus Testing and Care among Pregnant Women Using Commercial Claims Data, United States, 2011-2014
}

\author{
Aaron M. Harris (iD, Cheryl Isenhour, Sarah Schillie, and Claudia Vellozzi \\ Division of Viral Hepatitis, Centers for Disease Control and Prevention, Atlanta, GA, USA \\ Correspondence should be addressed to Aaron M. Harris; ieo9@cdc.gov
}

Received 18 January 2018; Accepted 13 February 2018; Published 1 April 2018

Academic Editor: Lu-Yu Hwang

Copyright (C) 2018 Aaron M. Harris et al. This is an open access article distributed under the Creative Commons Attribution License, which permits unrestricted use, distribution, and reproduction in any medium, provided the original work is properly cited.

\begin{abstract}
Introduction. Pregnant women should receive hepatitis B virus (HBV) testing with hepatitis B surface antigen (HBsAg), but it is unclear whether HBV-infected pregnant women are linked to care. Methods. We analyzed MarketScan ${ }^{\mathrm{TM}}$ commercial insurance claims. We included pregnant women, aged 10-50 years, with 42 weeks of continuous enrollment before (predelivery) and 6 months after (postdelivery) the first delivery claim for each unique pregnancy between 1/1/2011 and 6/30/2014. We identified claims for HBsAg testing by CPT code and described the care continuum among pregnancies with an associated ICD-9 HBV diagnosis code by demographic and clinical characteristics, including HBV-directed care ([HBV DNA or hepatitis B e antigen] and ALT test codes) and antiviral treatment (claims for tenofovir, entecavir, lamivudine, adefovir, or telbivudine) pre- and postdelivery. Results. There were 870,888 unique pregnancies (819,752 women) included. Before delivery, 714,830 (82\%) pregnancies had HBsAg test claims, but this proportion decreased with subsequent pregnancies $(p<0.0001)$ : second $(80 \%)$, third $(71 \%)$, and fourth $(61 \%)$. We identified $1,190(0.14 \%)$ pregnancies with an associated HBV diagnosis code: most were among women aged $\geq 30$ years $(76 \%)$ residing in the Pacific (34\%) or Middle Atlantic (18\%) regions. Forty-two percent of pregnancies with an HBV diagnosis received HBV-directed care (42\% predelivery and 39\% postdelivery). Antiviral treatment was initiated before delivery in 128 (13\%) of 975 pregnancies and postdelivery in $16(1.6 \%)$ pregnancies. Conclusions. While most of these commercially insured pregnant women received predelivery HBV screening, we identified gaps in HBV testing and the HBV care continuum which highlight potential targets for public health interventions.
\end{abstract}

\section{Introduction}

Hepatitis B virus (HBV) infection remains a major public health issue [1]. In the United States, an estimated 847,000 persons are living with chronic hepatitis $\mathrm{B}$ virus (HBV) infection [2], with about 14,000 attributable deaths annually [3]. Approximately one in four persons living with chronic $\mathrm{HBV}$ infection will die prematurely from liver cirrhosis, hepatocellular carcinoma, or liver failure [4].

Serologic testing for hepatitis B surface antigen (HBsAg) is the primary way to identify persons with $\mathrm{HBV}$ infection. The Advisory Committee on Immunization Practices (ACIP) recommends that all pregnant women receive $\mathrm{HBs}$ Ag testing during each pregnancy to identify infants needing postexposure prophylaxis [5]. There are approximately 25,000 infants born to HBsAg-positive pregnant women annually [6], and, without intervention, transmission can occur in up to $85 \%$ of exposed infants; among infected infants approximately $90 \%$ will become chronically $\mathrm{HBV}$-infected $[5,7]$. Infants born to HBsAg-positive women should receive hepatitis $\mathrm{B}$ vaccine and hepatitis $B$ immunoglobulin (HBIG) within 12 hours of birth, followed by completion of the hepatitis $\mathrm{B}$ vaccine series and postvaccination serologic testing [5]. Postexposure prophylaxis is up to $95 \%$ effective in preventing $\mathrm{HBV}$ transmission among infants born to HBsAg-positive mothers $[8,9]$. While prophylaxis has been successful in reducing maternal-to-child $\mathrm{HBV}$ transmission, there has been little support to address healthcare needs of mothers with HBV infection [10].

Prior studies have used claims data to study hepatitis B using International Classification of Diseases, Ninth Revision, Clinical Modification (ICD-9-CM) codes to identify persons with HBV who have liver cirrhosis [11] and antiviral treatment rates during pregnancy among women with 
HBV [12]. Claims data have also been used to assess the proportion of pregnant women receiving HBsAg testing [13]. We are not aware of previous studies that evaluated the complete HBV care continuum, from testing to linkage to care and treatment, among pregnant and postpartum women using claims data.

As a first step to address gaps in the HBV care continuum for pregnant women with $\mathrm{HBV}$ infection, we used commercial claims data to describe HBsAg testing during pregnancy and assess whether pregnant women with hepatitis B are linked to recommended care and antiviral treatment pre- and postdelivery.

\section{Methods}

2.1. Data Source and Study Population. We obtained demographic, enrollment, and insurance claims data from Truven Health's MarketScan Commercial Claims and Encounters insurance claims database, for women aged 10 to 50 years, from January 1, 2011, through June 30, 2014. This database includes claims for millions of persons with private insurance under the age of 65 years. A unique enrollee identification number allows linkage of medical claims with outpatient pharmacy claims data. This secondary analysis of deidentified insurance claims data did not require ethics approval.

To identify unique pregnancies during the study period, we searched medical claims for delivery-related diagnosis and procedure codes [12]. We defined the delivery index date for each pregnancy as the first service date on which a delivery-related code was documented. During the study period, women could have multiple unique pregnancies and associated delivery index dates, if all other study inclusion criteria were met. Specifically, for pregnancies to be included in the study, women were required to be continuously enrolled both 42 weeks before and 6 months following the delivery index date.

2.2. HBV Testing and Care Continuum Description and Statistical Analysis. To evaluate HBV testing, care, and treatment during pregnancy, we searched both inpatient and outpatient insurance claims for Current Procedural Terminology (CPT) codes, International Classification of Diseases, Ninth Revision, Clinical Modification (ICD-9-CM) procedure codes, and ICD-9-CM diagnosis codes associated with each cascade step (Table 1). We first calculated the proportion of all unique pregnancies with a claim for at least one HBsAg test during the 42 -week period prior to the delivery index date and also used the Cochran-Armitage test for trend to examine differences in HBsAg testing rates with each subsequent pregnancy.

We then described the HBV care continuum among all pregnancies in which the mother was diagnosed with chronic HBV, defined as at least one chronic HBV ICD9-CM diagnosis code (070.22, 070.23, 070.32, 070.33, or V02.61) documented on a claim prior to the delivery index date. Pregnancies with at least one HIV diagnosis code (795.71, V08, 042, or 079.53) documented on a claim prior to delivery were excluded because we sought to evaluate the $\mathrm{HBV}$ care continuum for HBV monoinfected women.
We defined engagement in $\mathrm{HBV}$-directed care as an alanine aminotransferase (ALT) test in conjunction with either an HBV DNA or hepatitis B e antigen ( $\mathrm{HBeAg}$ ) test, either before (up to 42 weeks before) or after (up to 6 months after) the delivery index date, and calculated the proportion of HBVinfected pregnancies in which the mother was engaged in care. Among a subset of pregnancies with pharmacy claims available for review, we calculated the proportion of $\mathrm{HBV}$ infected pregnancies in which the mother initiated HBV treatment, defined as at least one claim for antiviral treatment (tenofovir, entecavir, lamivudine, adefovir, or telbivudine) either before or after the delivery index date.

We fit simple logistic regression models, with general estimating equations to account for women with multiple pregnancies, to evaluate the differences in characteristics between pregnancies in which women did or did not receive recommended HBV care. Analyses were completed using SAS, version 9.3 (Cary, North Carolina). Statistical tests were considered significant at $p<0.05$.

\section{Results}

There were 870,888 unique pregnancies (819,752 women) included (Figure 1). Of these, 714,830 (82\%) had at least one HBsAg test claim prior to delivery. This proportion decreased with subsequent pregnancies $(p<0.0001$, Table 2$)$. HBsAg testing was more often performed in pregnancies occurring among women aged 20 to 39 years, residing in the North and South Central US, located in urban areas, and with a preferred provider organization (PPO) plan (Table 2). Lower HBsAg testing proportions were observed in pregnancies among women older than 40 years and those located in the Pacific census division.

We identified 1,190 of 870,888 (0.14\%) pregnancies (1146 women) with an associated HBV diagnosis code, and six pregnancies that had an associated HIV diagnosis code were excluded. The proportion of pregnancies during which the mother was diagnosed with HBV increased with increasing age and was higher during pregnancies occurring in urban areas (Table 3). In addition, there were a higher proportion of pregnancies during which the mother was diagnosed with $\mathrm{HBV}$ in the Pacific and Middle Atlantic census divisions (Table 3).

Among the 1,190 pregnancies with an HBV diagnosis code, 505 received $\mathrm{HBV}$-directed care. The proportion of pregnancies with $\mathrm{HBV}$-directed care was similar predelivery and postdelivery (501 [42\%] and 463 [39\%], resp.). While there were geographic differences noted among pregnancies with $\mathrm{HBV}$-directed care (with the greatest engagement in care among those in the West North Central and New England regions and the least engagement in care among those in the East North Central and Middle Atlantic regions), there were no significant differences by age groups, urbanicity, or insurance plan type of the women at the time of the pregnancy (Table 3).

Of the 1,190 pregnancies with an HBV diagnosis code, 975 (81.9\%) had pharmacy claims available for review. Antiviral treatment was prescribed during 144 (15\%) of these 975 pregnancies: predelivery in $128(13 \%)$ and postdelivery in $16(1.6 \%)$ 
TABle 1: Procedure ${ }^{\mathrm{a}}$ and diagnosis $\operatorname{codes}^{\mathrm{b}}$ used to identify hepatitis B diagnosis, testing, care, and treatment.

\begin{tabular}{|c|c|c|}
\hline Test or condition & Code number & Code description \\
\hline \multirow{3}{*}{ HBsAg test ${ }^{\mathrm{a}}$} & 87340 & Hepatitis B surface antigen \\
\hline & 80055 & Obstetric panel \\
\hline & 80074 & Acute hepatitis panel \\
\hline \multirow{5}{*}{$\mathrm{HBV}^{\mathrm{b}}$} & 070.22 & Chronic viral hepatitis B with hepatic coma without hepatitis delta \\
\hline & 070.23 & Chronic viral hepatitis B with hepatic coma with hepatitis delta \\
\hline & 070.32 & $\begin{array}{l}\text { Chronic viral hepatitis B without mention of hepatic coma without mention of } \\
\text { hepatitis delta }\end{array}$ \\
\hline & 070.33 & Chronic viral hepatitis B without mention of hepatic coma with hepatitis delta \\
\hline & V02.61 & Hepatitis B carrier \\
\hline \multirow{2}{*}{ ALT test $^{\mathrm{a}}$} & 80076 & Hepatic Function Panel \\
\hline & 84460 & Alanine Aminotransferase (ALT) \\
\hline \multirow{3}{*}{ HBV DNA test ${ }^{\mathrm{a}}$} & 87515 & Hepatitis B virus detection by nucleic acid using direct probe technique \\
\hline & 87516 & Hepatitis B Virus DNA, Qualitative, Real-Time PCR \\
\hline & 87517 & Hepatitis B Virus DNA, Quantitative, Real-Time PCR \\
\hline HBeAg test $^{\mathrm{a}}$ & 87350 & Hepatitis Be Antigen \\
\hline Newborn live birth ${ }^{\mathrm{b}}$ & V30-V39 & Live born infants according to type of birth \\
\hline \multirow{2}{*}{ HBIG administered ${ }^{\mathrm{a}}$} & $\mathrm{J} 1573$ & Injection, hepatitis b immune globulin \\
\hline & 90371 & Hepatitis B immune globulin \\
\hline \multirow{6}{*}{ Hep B vaccine ${ }^{\mathrm{a}}$} & 90739 & Hepatitis B vaccine (HepB), adult dosage, 2 dose schedule, for intramuscular use \\
\hline & 90740 & $\begin{array}{l}\text { Hepatitis B vaccine, dialysis or immunosuppressed patient dosage ( } 3 \text { dose } \\
\text { schedule), for intramuscular use }\end{array}$ \\
\hline & 90743 & Hepatitis B vaccine, adolescent (2 dose schedule), for intramuscular use \\
\hline & 90744 & $\begin{array}{l}\text { Hepatitis B vaccine, pediatric/adolescent dosage ( } 3 \text { dose schedule), for } \\
\text { intramuscular use }\end{array}$ \\
\hline & 90746 & Hepatitis B vaccine, adult dosage ( 3 dose schedule), for intramuscular use \\
\hline & 90747 & $\begin{array}{l}\text { Hepatitis B vaccine, dialysis or immunosuppressed patient dosage ( } 4 \text { dose } \\
\text { schedule), for intramuscular use }\end{array}$ \\
\hline
\end{tabular}

${ }^{a}$ Current Procedural Terminology or Healthcare Common Procedure Coding System. ${ }^{b}$ International Classification of Diseases, Ninth Edition, Clinical Modification.

(Table 4). There were no significant differences in maternal demographic characteristics for antiviral prescription status. Tenofovir (76\%) was the most commonly prescribed antiviral medication followed by lamivudine (10\%) and entecavir (9\%); adefovir and telbivudine make up the remaining 5\%.

\section{Discussion}

Using commercial claims data, we evaluated HBsAg testing practices and the HBV care continuum among commercially insured pregnant women. Most pregnancies (82\%) had HBsAg test claim and 1,190 (0.14\%) had an HBV diagnosis code. Our data demonstrated a gap in linkage to care among commercially insured pregnant women with $\mathrm{HBV}$, as only $42 \%$ of pregnancies had claims suggesting $\mathrm{HBV}$-directed care engagement. Furthermore, while an estimated 25\% of persons with chronic $\mathrm{HBV}$ infection are treatment eligible, our study showed only $13 \%$ of pregnancies with an $\mathrm{HBV}$ diagnosis code were prescribed an antiviral prior to delivery, and $1.6 \%$ had an antiviral prescription postdelivery; however, we did not assess treatment eligibility (e.g., HBV DNA > $200,000 \mathrm{IU} / \mathrm{mL}$ ) among these pregnancies.
Of a population of pregnant women with private health insurance, we showed many pregnancies (18\%) without evidence of HBsAg test claim. CDC recommends that all pregnant women should be tested for HBsAg during an early prenatal visit (e.g., first trimester) in each pregnancy, even if they have been previously vaccinated or tested [5]. Testing provides documentation of the positive HBsAg test result and helps to ensure that infants will be identified for timely prophylaxis [5]. Previous data using MarketScan showed that $12 \%$ of insured pregnant women did not receive $\mathrm{HBsAg}$ testing [13], which differed from our data, possibly due to methodologic differences in amount of time in continuous enrollment (15 months in our study versus 12 months) and age groups included (10-50 years in our study versus 15-44 years). We also included more years of data (2011-2014 versus 2013-2014). Our analysis showed that women aged 20-39 years had higher testing proportions than women aged 40 years or older. This is consistent with the decreased proportion of women receiving $\mathrm{HBs}$ Ag testing in subsequent pregnancies. While it is reassuring that a large proportion of pregnant women receive HBsAg testing, strategies are needed to get closer to $100 \% \mathrm{HBsAg}$ testing. 


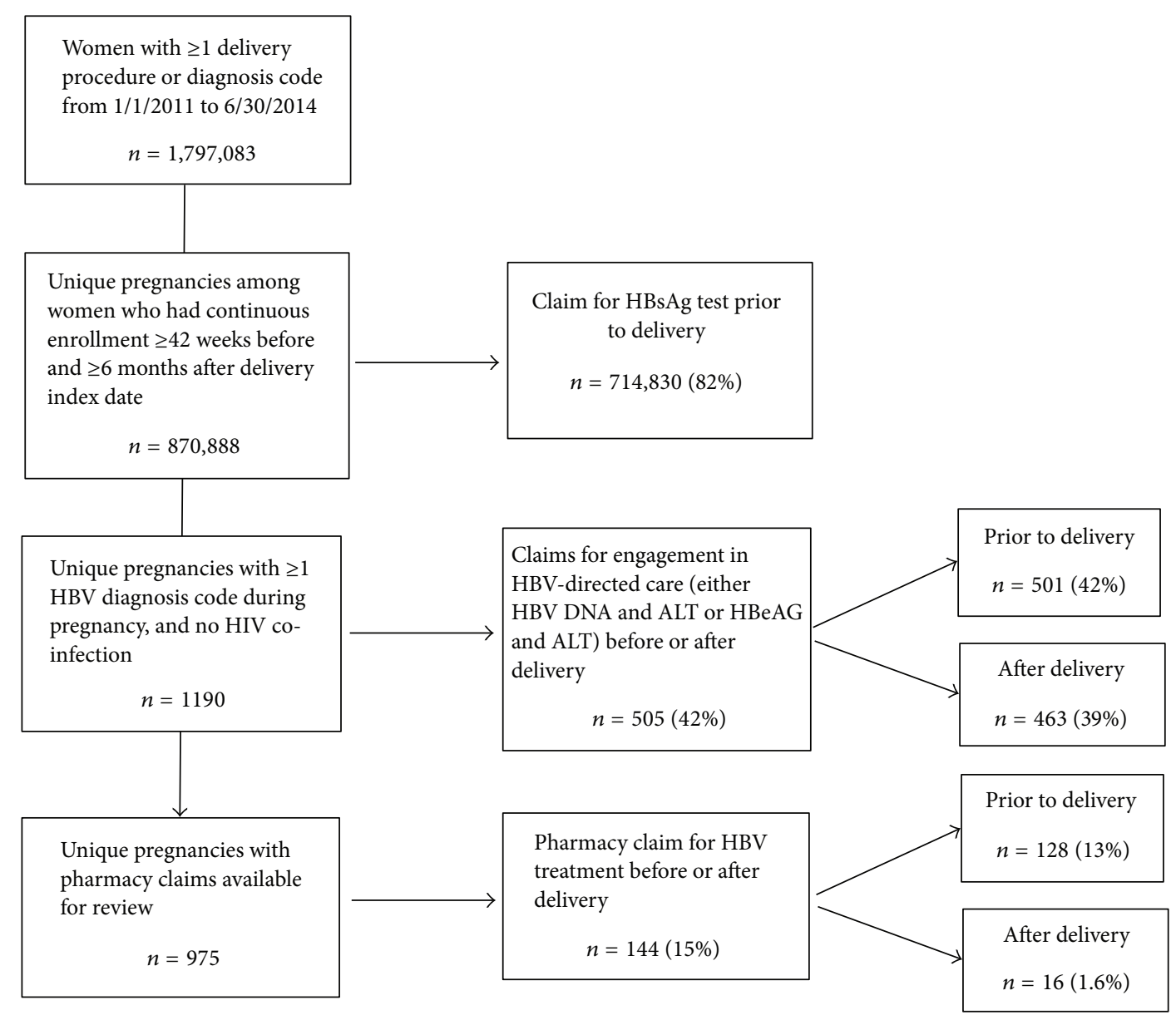

FIGURE 1: Flow chart of study criteria and cascade of hepatitis B testing, care, and treatment among pregnancies in MarketScan, $2011-2014$.

Nationally and regardless of pregnancy status, few persons with $\mathrm{HBV}$ are linked to care and many public health efforts are underway to fill this gap [14, 15]. Even though a large number of pregnant women received HBsAg testing, many HBsAg-positive women were not linked to care [10]. Our data indicated that $58 \%$ of pregnancies with an associated $\mathrm{HBV}$ diagnosis code were not linked to appropriate $\mathrm{HBV}$ care either during pregnancy or postpartum. There were geographic differences for linkage to care; however, there were not significant differences for HBV linkage to care identified during pregnancy in urban versus nonurban areas. In addition to reducing maternal-to-child transmission, HBsAg testing during pregnancy provides an opportunity to link women to care. Linking HBsAg-positive pregnant women to HBV-directed care is the critical second step in the care continuum to identify those who may benefit from antiviral therapy which can delay $\mathrm{HBV}$-associated liver complications and prevent maternal-to-child transmission.

In addition to prophylaxis for infants born to HBsAgpositive women, pregnant women with $\mathrm{HBV}$ may require antiviral treatment. The American Association for the Study of Liver Diseases (AASLD) guidelines suggest maternal antiviral therapy when the maternal HBV DNA is >
200,000 IU/mL [16]. Regarding antiviral treatment prescriptions, a prior analysis using commercial claims data showed a $13 \%$ antiviral prescription rate overall among pregnant women, which was significantly lower than that among nonpregnant women (20\%) with HBV [12]. About 25\% of persons with HBV are eligible for antiviral therapy [14]. Our data showed that $15 \%$ of pregnant women with an $\mathrm{HBV}$ diagnosis code were prescribed an antiviral overall and only $1.6 \%$ were prescribed an antiviral postdelivery. Tenofovir is first-line antiviral medication for treatment eligible pregnant women, although lamivudine or telbivudine has also been used as there is no evidence of adverse outcomes in infants born to mothers treated with these agents [16]. Although 11 pregnant women were treated with entecavir predelivery, entecavir is not recommended because the safety during pregnancy is not known. Our analysis showed that tenofovir was most commonly used, followed by lamivudine and entecavir. We did not include interferon in our analysis because it is contraindicated during pregnancy. Even though our analysis included claims data between 2011 and 2014, which is prior to the publication of updated AASLD clinical guidelines in 2016 [16], our analysis demonstrated significant linkage to care and treatment gaps among pregnant women with HBV. 
TABLE 2: Hepatitis B screening among 870,888 pregnancies in commercial insurance claims data, 2011-2014.

\begin{tabular}{|c|c|c|c|c|}
\hline & & & & \\
\hline & Total & $n$ & Row\% & $p$ value $^{\mathrm{c}}$ \\
\hline Total & $870,888^{\mathrm{b}}$ & 714,830 & 82.08 & \\
\hline Pregnancy & & & & $<0.001$ \\
\hline 1st pregnancies & 795,870 & 655,218 & 82.33 & \\
\hline 2nd pregnancies & 73,247 & 58,359 & 79.67 & \\
\hline 3rd pregnancies & 1,743 & 1,236 & 70.91 & \\
\hline 4th pregnancies & 28 & 17 & 60.71 & \\
\hline Age group & & & & $<0.001$ \\
\hline 19 or younger & 39,067 & 28612 & 73.24 & \\
\hline 20 to 29 & 356,474 & 300727 & 84.36 & \\
\hline 30 to 39 & 438,844 & 363708 & 82.88 & \\
\hline 40 or older & 36,503 & 21783 & 59.67 & \\
\hline Census division $^{\mathrm{d}}$ & & & & $<0.001$ \\
\hline New England & 40,403 & 32,767 & 81.10 & \\
\hline Middle Atlantic & 102,312 & 80,774 & 78.95 & \\
\hline East North Central & 161,920 & 130,865 & 80.82 & \\
\hline West North Central & 45,137 & 38,475 & 85.24 & \\
\hline South Atlantic & 153,566 & 128,662 & 83.78 & \\
\hline East South Central & 52,726 & 45,441 & 86.18 & \\
\hline West South Central & 100,916 & 89,101 & 88.29 & \\
\hline Mountain & 56,611 & 47,470 & 83.85 & \\
\hline Pacific & 134,756 & 103,260 & 76.63 & \\
\hline Other/unknown & 22,541 & 18,015 & 79.92 & \\
\hline Urbanicity $^{\mathrm{e}}$ & & & & $<0.001$ \\
\hline Nonurban & 106,490 & 85,273 & 80.08 & \\
\hline Urban & 745,585 & 613,825 & 82.33 & \\
\hline Insurance plan type ${ }^{f}$ & & & & $<0.001$ \\
\hline Managed care $\mathrm{g}^{\mathrm{g}}$ & 207,179 & 159,265 & 76.87 & \\
\hline PPO or other ${ }^{\mathrm{h}}$ & 637,739 & 533,989 & 83.73 & \\
\hline
\end{tabular}

Boldface indicates statistical significance $(p<0.05) ;{ }^{a} \mathrm{HBsAg}=$ hepatitis B surface antigen. ${ }^{\mathrm{b}}$ Among 819,752 women continuously enrolled 42 weeks before and 6 months after first delivery CPT or ICD-9-CM diagnosis code (Table 1). ${ }^{c}$ Logistic regression models with general estimating equations to account for women with multiple pregnancies during the study period. ${ }^{\mathrm{d}}$ New England $=\mathrm{CT}, \mathrm{MN}, \mathrm{MA}, \mathrm{NH}, \mathrm{RI}, \mathrm{VA}$; Middle Atlantic = NJ, NY, PA; East North Central = IN, IL, MI, OH, WI; West North Central = IA, KS, MN, MO, NB, ND, SD; South Atlantic = DC, DE, FL, GA, MD, NC, SC, VA, WV; East South Central = AL, KY, MS, TN; West South Central = AR, LA, OK, TX; Mountain: AZ, CO, ID, NM, MT, UT, NV, WY; Pacific = AK, CA, HI, OR, WA; and other/unknown = Puerto Rico and unknown state of residence. ${ }^{\mathrm{e}}$ Urbanicity was determined by metropolitan statistical area (MSA); $15,732 \mathrm{HBsAg}$ tested of 18,813 (83.6\%) were missing urbanicity; ${ }^{\mathrm{f}} 21,576 \mathrm{HBsAg}$ tested of 25,970 (83.1\%) were missing insurance plan type. ${ }^{\mathrm{g}}$ Health maintenance organizations (HMO), exclusive provider organizations (EPO), and point of Service (POS) plans. ${ }^{\mathrm{h}}$ Preferred provider organizations (PPO), high deductible, and comprehensive plans.

Our analysis was subject to at least five limitations. First, we used a commercially insured claims database that does not include women without insurance and therefore does not represent the general US population. The HBV care continuum among under- or uninsured women and children still needs to be characterized to better target public health interventions. Second, there may have been misclassification related to claim codes used to identify pregnant women. For instance, if a claim was not submitted or reimbursed, it may not have been captured in the dataset, thereby leading to an underestimated sample. Third, there was potential for misclassification of HBsAg testing. We included a broad set of codes to include all potential HBV diagnoses; however, codes may have not equated to actual HBV infection as we were unable to confirm infection status with laboratory results or medical record review. Fourth, not all women had prescription claims data available for analysis, which may have led to an underestimated proportion of women receiving antiviral prescriptions. Fifth, we were not able to ascertain the proportion of pregnancies that would have been eligible for treatment, such as those with HBV DNA > 200,000 IU/mL, because we did not have laboratory data. In addition, since we defined care engagement as having one ALT, HBV DNA, or $\mathrm{HBeAg}$, we were unable to assess continued follow-up care beyond initial care engagement. However, our results are consistent with other published data [12].

There have been several strategies identified that lead to increased testing and linkage to care for persons with HBV that may be applied to address gaps for pregnant women with HBV infection identified in this study. Patient education 


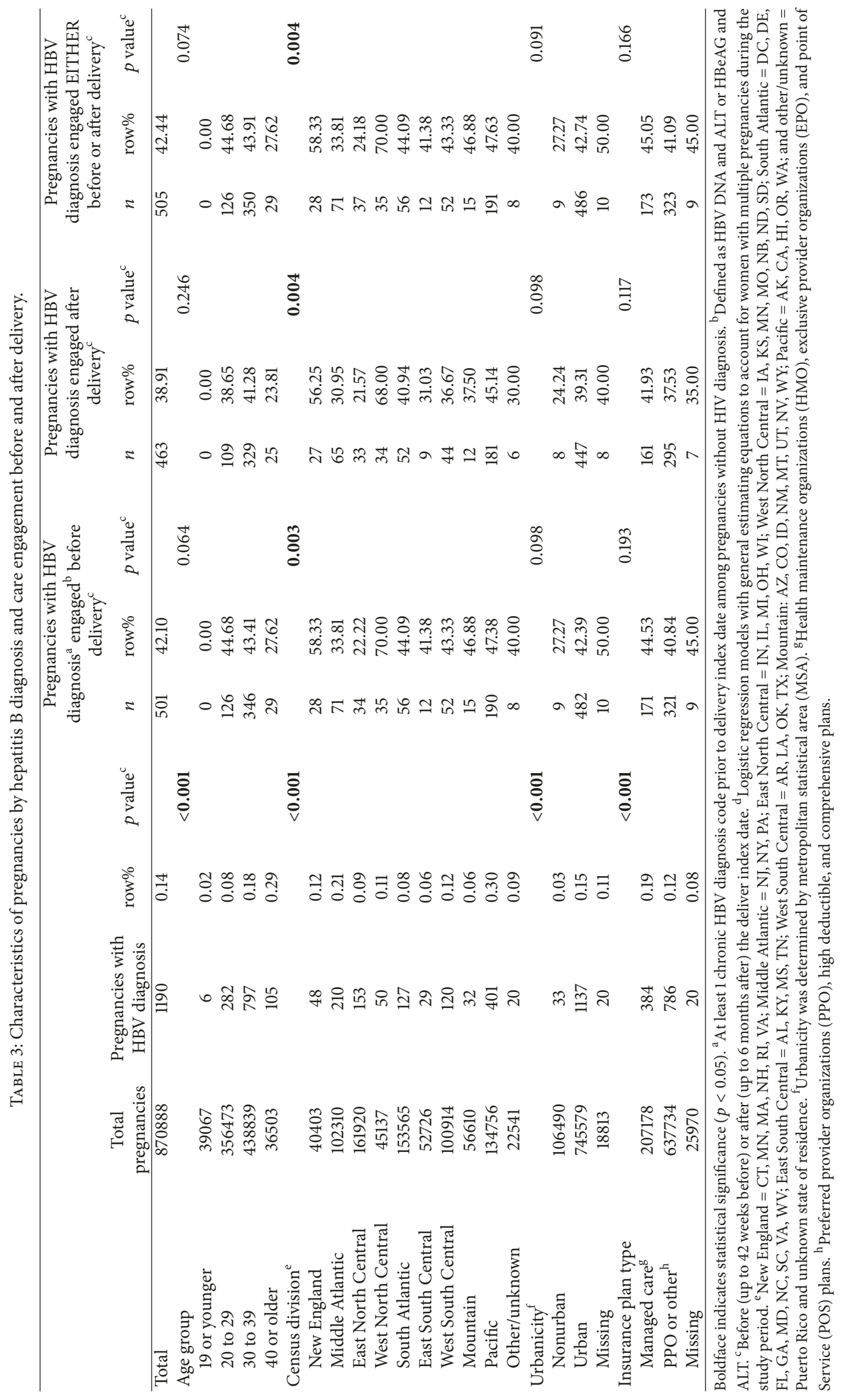




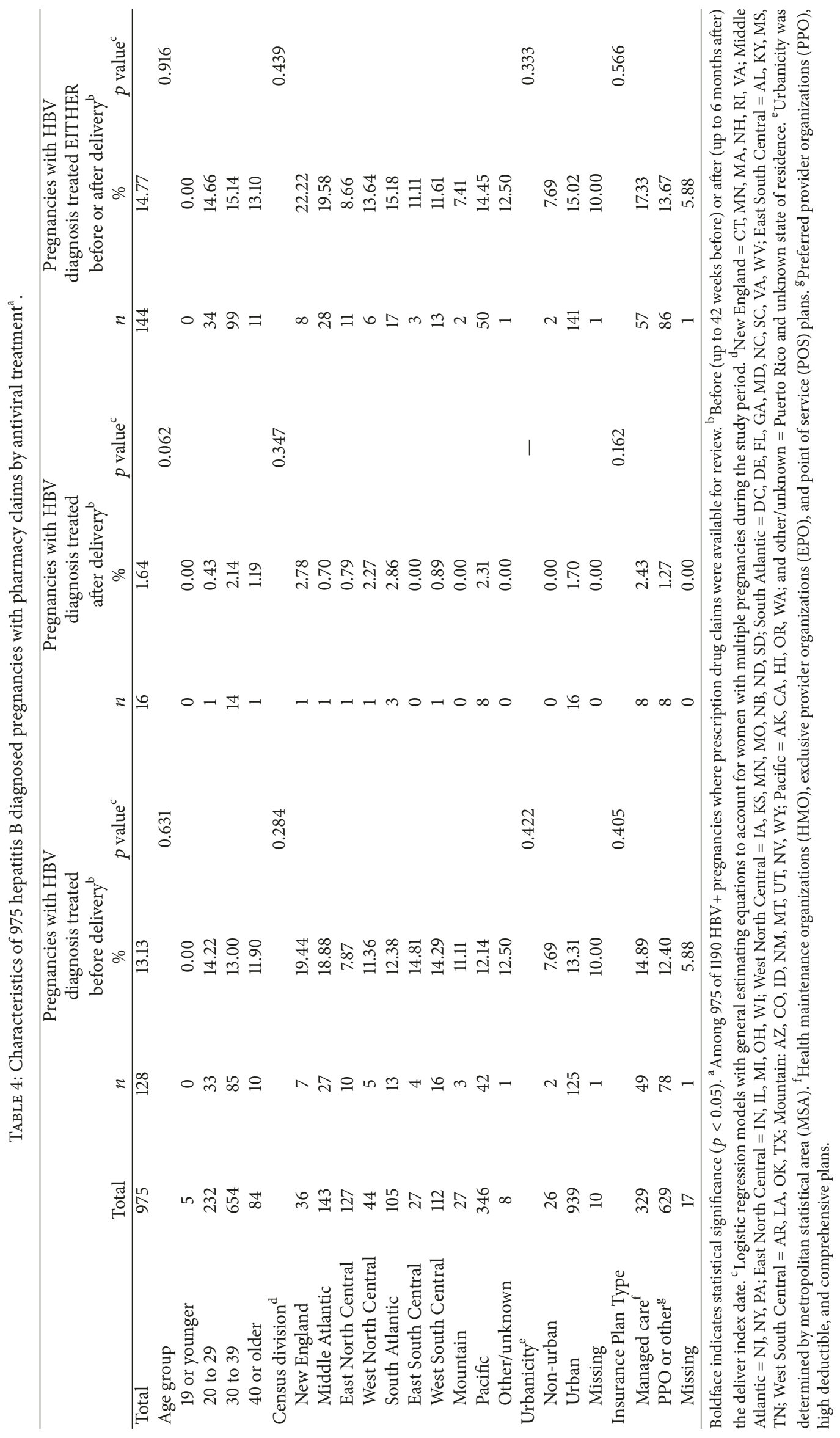


has shown success by facilitating increased HBV testing in hard to reach populations $[15,17,18]$ and can be applied to pregnant women. In addition, provider education is important to ensure HBV testing is performed and correctly interpreted, and persons with positive results receive appropriate management [19], which can be applied to prenatal care clinics. Coordination of care through care managers or peer navigators has been shown to increase linkage to care $[15,20]$ and can be applied postdelivery to mothers identified with HBV. Utilization of health information technology may increase hepatitis B testing for pregnant women and prompt the provider to order appropriate HBV tests both pre- and postdelivery [21]. Further study is warranted to identify best practice strategies to increase linkage to care for pregnant women with HBV infection.

\section{Conclusion}

Commercial claims data can be used to evaluate the hepatitis $\mathrm{B}$ care continuum among commercially insured pregnant women. Our data showed that many pregnant women received predelivery hepatitis $\mathrm{B}$ testing; however testing should approach $100 \%$ among a commercially insured population. Furthermore we identified gaps in the hepatitis B care continuum among HBV-infected women which highlight potential targets for public health interventions to decrease HBV-associated morbidity and mortality among pregnant women and their infants.

\section{Data Availability}

MarketScan data is publically available.

\section{Disclosure}

The findings and conclusions in this report are those of the authors and do not necessarily represent the official position of the Centers for Disease Control and Prevention. This work was presented at the American Public Health Association 2017 Annual Meeting in Atlanta, GA, on November 7, 2017 (abstract number 4049.0).

\section{Conflicts of Interest}

The authors have no financial conflicts of interest.

\section{Authors' Contributions}

Dr. Aaron M. Harris helped design the study, supervised the analytic plan, interpreted the data, drafted the initial manuscript, revised the manuscript, and approved the final manuscript; Dr. Cheryl Isenhour managed the database, helped design the study, led the data analysis and interpretation, critically reviewed the manuscript, and approved the final manuscript; Dr. Sarah Schillie contributed to study design, critically reviewed the manuscript as a subject matter expert, helped interpret the data, and approved the final manuscript as submitted; Dr. Claudia Vellozzi obtained funding to conduct the study, supervised Drs. Cheryl Isenhour and Aaron M. Harris in the analysis and scientific writing, critically reviewed and revised the manuscript, and approved the final manuscript as submitted.

\section{Acknowledgments}

This study was funded by the Centers for Disease Control and Prevention.

\section{References}

[1] A. Schweitzer, J. Horn, R. T. Mikolajczyk, G. Krause, and J. J. Ott, "Estimations of worldwide prevalence of chronic hepatitis $B$ virus infection: a systematic review of data published between 1965 and 2013," The Lancet, vol. 386, no. 10003, pp. 1546-1555, 2015.

[2] H. Roberts, D. Kruszon-Moran, K. N. Ly et al., "Prevalence of chronic hepatitis B virus (HBV) infection in U.S. households: National Health and Nutrition Examination Survey (NHANES), 1988-2012," Hepatology, vol. 63, no. 2, pp. 388-397, 2016.

[3] T. Mitchell, G. L. Armstrong, D. J. Hu, A. Wasley, and J. A. Painter, "The increasing burden of imported chronic hepatitis B-United States, 1974-2008," PLoS ONE, vol. 8, no. 3, pp. 101371, 2013.

[4] A. S. Lok and B. J. McMahon, "Chronic hepatitis B: update 2009," Hepatology, vol. 50, no. 3, pp. 661-662, 2009.

[5] E. E. Mast, H. S. Margolis, A. E. Fiore et al., "A comprehensive immunization strategy to eliminate transmission of hepatitis $B$ virus infection in the United States: recommendations of the Advisory Committee on Immunization Practices (ACIP) part 1: immunization of infants, children, and adolescents," MMWR Recommendations and Reports, vol. 54, no. 16, pp. 1-32, 2005.

[6] E. A. Smith, L. Jacques-Carroll, T. Y. Walker, B. Sirotkin, and T. V. Murphy, "The national perinatal hepatitis B prevention program, 1994-2008," Pediatrics, vol. 129, no. 4, pp. 609-616, 2012.

[7] S. Schillie, T. Walker, S. Veselsky et al., "Outcomes of infants born to women infected with hepatitis B," Pediatrics, vol. 135, no. 5, pp. e1141-e1147, 2015.

[8] R. P. Beasley, G. Chin-Yun Lee, C.-H. Roan et al., "Prevention of perinatally transmitted hepatitis B virus infections with hepatitis B immune globulin and hepatitis B vaccine," The Lancet, vol. 322, no. 8359, pp. 1099-1102, 1983.

[9] C. Lee, Y. Gong, J. Brok, E. H. Boxall, and C. Gluud, "Effect of hepatitis B immunisation in newborn infants of mothers positive for hepatitis B surface antigen: systematic review and metaanalysis," British Medical Journal, vol. 332, no. 7537, pp. 328-332, 2006.

[10] R. Rajbhandari, K. Barton, A. C. Juncadella et al., "Discontinuity of care for mothers with chronic hepatitis B diagnosed during pregnancy," Journal of Viral Hepatitis, vol. 23, no. 7, pp. 561-568, 2016.

[11] B. Niu, K. A. Forde, and D. S. Goldberg, "Coding algorithms for identifying patients with cirrhosis and hepatitis B or C virus using administrative data," Pharmacoepidemiology and Drug Safety, vol. 24, no. 1, pp. 107-111, 2015.

[12] L. Fan, K. Owusu-Edusei, S. F. Schillie, and T. V. Murphy, "Antiviral treatment among pregnant women with chronic 
hepatitis B,' Infectious Diseases in Obstetrics and Gynecology, vol. 2014, Article ID 546165, 7 pages, 2014.

[13] M. S. Kolasa, Y. Tsai, J. Xu, N. Fenlon, and S. Schillie, "Hepatitis B surface antigen testing among pregnant women, United States 2014," The Pediatric Infectious Disease Journal, vol. 36, no. 7, pp. e175-e180, 2017.

[14] C. Cohen, S. D. Holmberg, B. J. McMahon et al., "Is chronic hepatitis B being undertreated in the United States?" Journal of Viral Hepatitis, vol. 18, no. 6, pp. 377-383, 2011.

[15] A. M. Harris, B. T. Schoenbachler, G. Ramirez, C. Vellozzi, and G. A. Beckett, "Testing and linking foreign-born people with chronic hepatitis B virus infection to care at nine U.S. Programs, 2012-2014," Public Health Reports, vol. 131, pp. 20-28, 2016.

[16] N. A. Terrault, N. H. Bzowej, K.-M. Chang, J. P. Hwang, M. M. Jonas, and M. H. Murad, "AASLD guidelines for treatment of chronic hepatitis B," Hepatology, vol. 63, no. 1, pp. 261-283, 2016.

[17] A. Nishimura, P. Shiono, D. Stier, S. Shallow, M. Sanchez, and S. Huang, "Knowledge of hepatitis B risk factors and prevention practices among individuals chronically infected with hepatitis B in San Francisco, California," Journal of Community Health, vol. 37, no. 1, pp. 153-158, 2012.

[18] C. Jorgensen, S. Chen, C. A. Carnes et al., ““Know hepatitis B:” A multilingual communications campaign promoting testing for hepatitis B among Asian Americans and pacific islanders," Public Health Reports, vol. 131, pp. 35-40, 2016.

[19] J. M. Ferrante, D. G. Winston, P.-H. Chen, and A. N. De La Torre, "Family physicians' knowledge and screening of chronic hepatitis and liver cancer," Journal of Family Medicine, vol. 40, no. 5, pp. 345-351, 2008.

[20] G. Ramirez, R. Cabral, M. Patterson et al., "Early identification and linkage to care for people with chronic HBV and HCV infection: the HepTLC initiative," Public Health Reports, vol. 131, pp. 5-11, 2016.

[21] L. Hsu, C. L. Bowlus, S. L. Stewart et al., "Electronic messages increase hepatitis B screening in at-risk Asian American patients: a randomized, controlled trial," Digestive Diseases and Sciences, vol. 58, no. 3, pp. 807-814, 2013. 


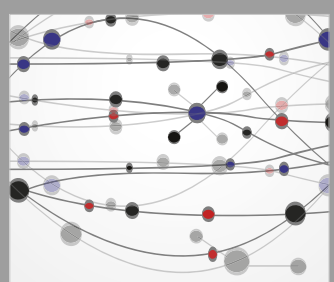

The Scientific World Journal
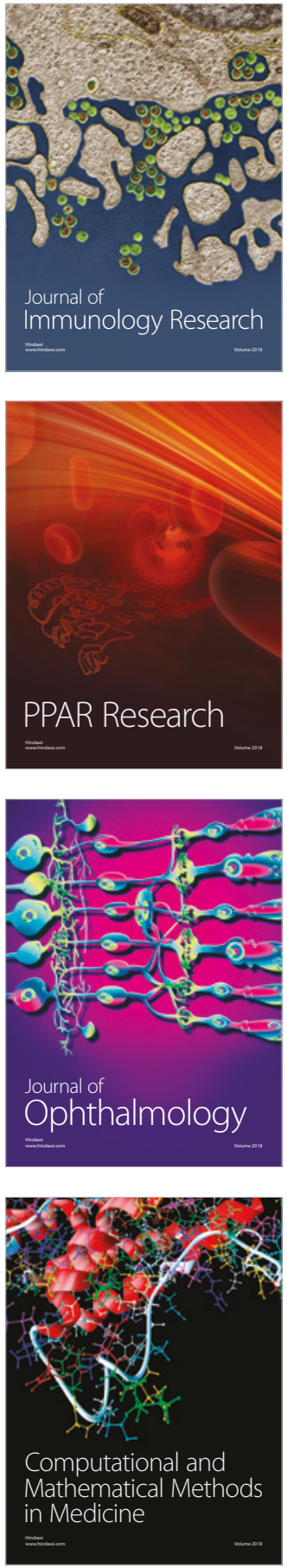

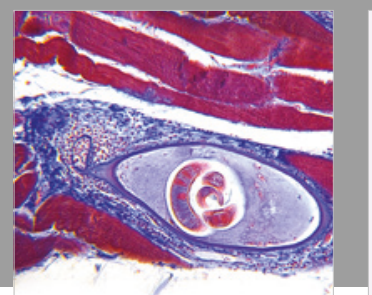

Gastroenterology Research and Practice

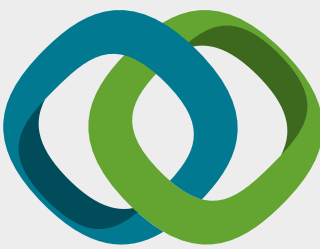

\section{Hindawi}

Submit your manuscripts at

www.hindawi.com
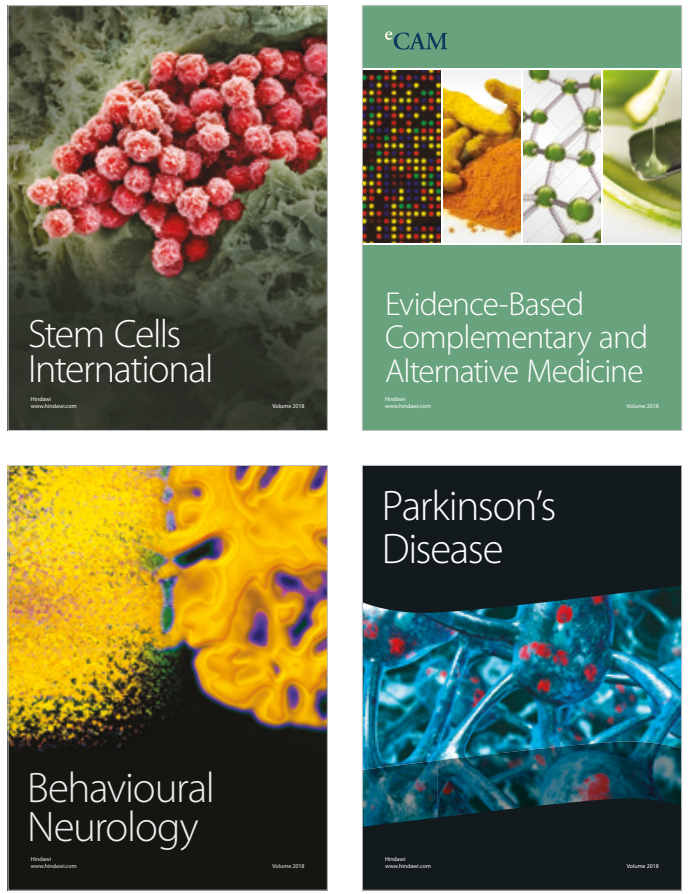

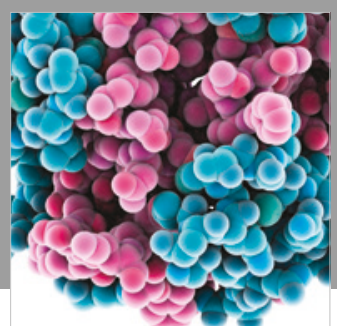

ournal of

Diabetes Research

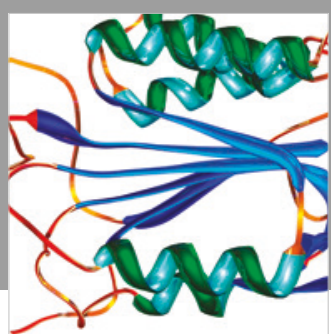

Disease Markers
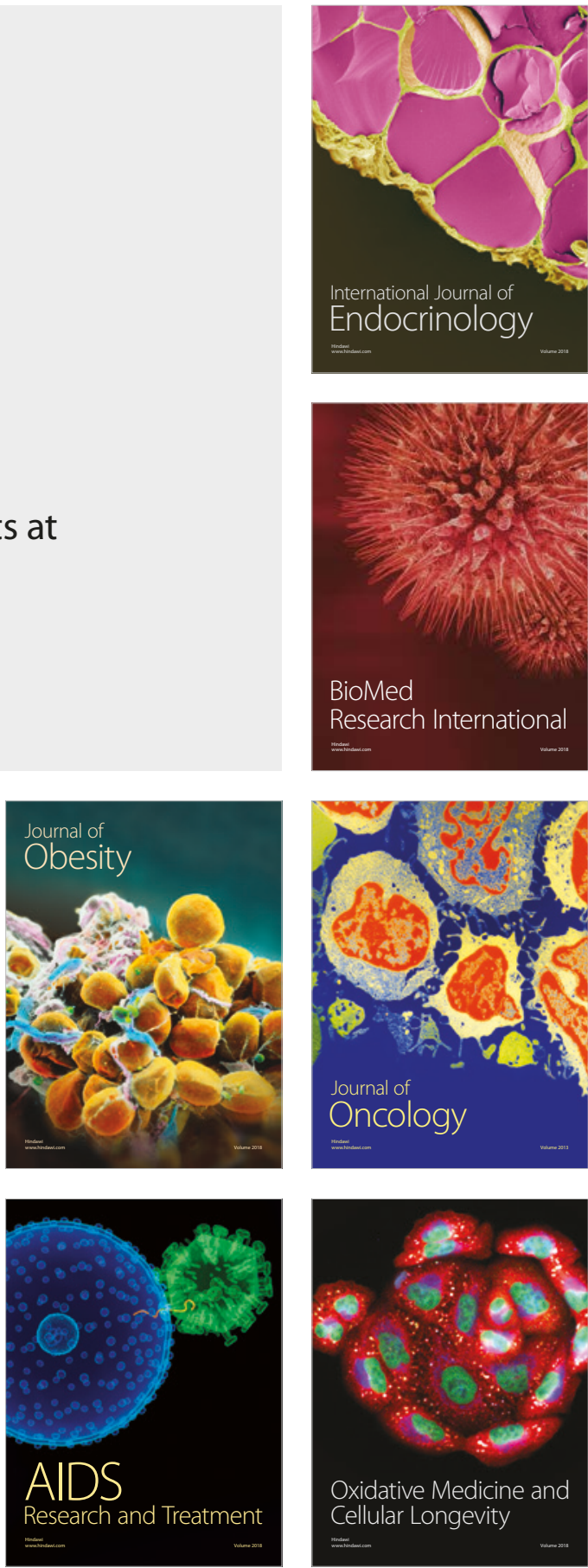